\title{
Radiology in Kenya
}

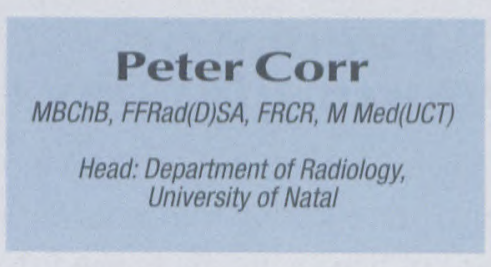

Onar $n$ a recent visit as external examiner to the Department of Radiology, University of Nairobi, I had the opportunity to meet a number of radiologists at their practices and give a lecture to the Kenyan Association of Radiologists.

Kenya, with Tanzania and Uganda, forms part of the East African region. Kenya has a population of 25 million people, most of whom live in the central highlands, the coastal region, the Rift valley and around Nairobi. Nairobi is the capital city with a population of 3 million.

There are 35 radiologists in Kenya, most of whom are resident in Nairobi. The Jomo Kenyatta Hospital is the main teaching hospital of the University of Nairobi. The hospital is only 20 years old with 2000 beds and full specialist services. The radiology department has both University and Government sectors with ten consultants, a professor and senior lecturers. The department has been training radiologists from East Africa since the mid-seventies. Fifty radiologists have graduated with the Master of Medicine degree. It is a three-year programme, very similar to the Royal College of Radiologists training.

The hospital has a CT scanner, biplanar angiography unit, ten bucky rooms, three fluoroscopy rooms and a gamma camera. A new colour flow ultrasound unit has been installed. The hospital is very busy with a large out-patient workload. As in many African countries, the paediatric patient load is very heavy. The registrars and doctors are keen to learn and expand services, especially in interventional work and Doppler ultrasound. The chairman of the department is very keen to receive radiologists who would like to give a lecture or spend some time teaching in the department.

The private diagnostic clinics and the Aga Khan hospital in the city are well run and extremely well equipped with two MR scanners, and a third scanner is likely to be installed next year.

The Kenyan Association of Radiologists is a small but active radiology society with monthly academic meetings and an annual academic meeting. The last annual meeting was in Mombasa, held in conjunction with the Scottish Radiology Society. The association is keen to foster links with our society and possibly have a joint meeting in the future.

My impression of Kenyan radiology was very positive. The Kenyan Association is led by young dynamic radiologists who are keen to encourage the development of radiology in Kenya despite the many financial difficulties that the country faces. Kenya is undoubtedly one of the most beautiful countries on the African continent to visit. I feel that our society should encourage links with the Kenyan Association with future visits and joint meetings. 